\title{
A COMMEDIA DELL'ARTE COMO MÉTODO DE PREPARAÇÃO DO ATOR CONTEMPORÂNEO
}

Paula Scheidt Manoel ${ }^{1}$

\section{INTRODUÇÃO}

Surgida em contraponto ao teatro tradicional e baseada no grotesco dos arquétipos humanos, a commedia dell'arte foi resgatada no século 20 como método de preparação de atores, por encenadores como Jacques Lecoq e Ariane Mnouchkine, fundadora do Théâtre du Soleil, entre outros. Esse artigo pretende apresentar as características desse gênero teatral, metodologias para o treinamento do ator e exemplos da prática empregada pela Companhia Cênica Origem, fundada no âmbito do Grupo de Pesquisa "Artes Cênicas na sua Escola" do Curso de Artes Cênicas da Universidade Federal de Santa Catarina (UFSC), coordenado pela professora Maria de Fátima de Souza Moretti. Com isso, espera-se mostrar os benefícios para o ator contemporâneo do emprego de tais práticas no trabalho de preparação corporal e vocal.

\section{METODOLOGIA}

O trabalho foi desenvolvido com base em pesquisas teóricas e práticas. A revisão bibliográfica inclui autores como Dario Fo (1987), Margot Berthold (2008) e Jacques Lecoq (2010), iniciadas em março de 2014. Foram construídas máscaras em moldes próprios para os atores integrantes da Companhia Cênica Origem no período de abril e maio de 2014. A próxima etapa foi o início da pesquisa corporal e experimentações com as máscaras criadas, de junho a setembro, seguida da preparação de um espetáculo baseado nas improvisações desenvolvidas pelos atores.

1 Curso de Artes Cênicas da Universidade Federal de Santa Catarina (UFSC) paulascheidt@gmail.com 
O espetáculo foi apresentado durante a V Mostra Acadêmica de Artes Cênicas em outubro de 2014. Em novembro, o grupo participou de uma oficina intensiva com os atores italianos especializados em commedia dell'arte Massimiliano Buldrini e Paula Noelia Cianfagna.

Ao longo de 2015, foram realizadas pesquisas de aprofundamento da técnica, explorando metodologias de aplicação do treinamento tradicional de commedia dell'arte para 0 ator contemporâneo. Em outubro, uma nova apresentação foi executada durante a VI Mostra Acadêmica de Artes Cênicas e o grupo participou de uma oficina intensiva com o professor da Universidade de Ulster (UK), Giuliano Campo, o qual também desenvolve pesquisa prática nesse campo.

Com isso, é possível analisar os benefícios para o ator na prática de exercícios na commedia dell'arte para a atividade profissional, independente do gênero teatral a ser seguido.

\section{HISTÓRIA DA COMMEDIA DELL'ARTE}

Espontaneidade, improviso, agilidade e habilidade são algumas palavras que podem ser relacionadas ao gênero teatral denominado commedia dell'arte. Berthold (2008, p. 353) a define como sendo uma,

arte mimética segundo a inspiração do momento, improvisação ágil, rude e burlesca, jogo teatro primitivo tal como na Antiguidade os atelanos haviam apresentado em seus palcos itinerantes: o grotesco dos tipos segundo esquemas básicos de conflitos humanos, demasiadamente humanos, a inesgotável, infinitamente variável e, em última análise, sempre inalterada matéria-prima dos comediantes no grande teatro do mundo. Mas isto também significa domínio artístico dos meios de expressão do corpo, reservatório de cenas prontas para a apresentação e modelos de situações, combinações engenhosas, adaptação espontânea do gracejo à situação do momento. (lbid) .

Como explica Fo (1987, p. 11), a palavra "Arte" era empregada na Idade média para se referir ao trabalho do artesão. Mais especificamente, commedia dell'arte significa, segundo o autor, "comédia preparada por atores profissionais, associações com um estatuto próprio de leis e regras, através dos quais os cômicos obrigavam-se a proteger-se e respeitar-se reciprocamente" (Ibid, 12). 
Historicamente existem teóricos, como Diderot, que defendem a supremacia do texto sobre outros elementos do teatro. Fo (lbid) critica esse posicionamento para defender a relevância da commedia dell'arte para o desenvolvimento do teatro. Ele ressalta que o frescor do improviso presente nesse gênero é que faz a palavra no teatro ser viva, fazendo com que ela apareça com força todas as noites sobre o palco. $O$ autor rebate também a crítica de que grupos de commedia dell'arte eram formados por pessoas sem cultura, quase analfabetos ou "puro cafetões". Fo afirma que acontecia justamente o contrário. "O teatro de comédia, aquele que entrou na história do espetáculo de toda a Europa por pelo menos três séculos, é construído por grupos de gente culta, com preparo e gosto moderno" (Ibid, p. 16, tradução nossa)2.

O primeiro testemunho oficial da prática da commedia dell'arte remonta 0 ano de 1545, na Itália. Segundo Buldrini e Cianfagna (2014), ela pode ser dividida em três períodos históricos, cada qual com características singulares. Em todas as fases, o uso da máscara é uma característica fundamental, assim como o emprego dos tipos humanos. O que varia é, principalmente, o modo de interpretação e as regiões por onde circulavam os grupos.

A primeira fase, que vai do século XVI ao XVIII, é caracterizada por uma comédia mais terrena, com personagens estereotipados e mais selvagens. Os artistas se adaptavam ao público, fazendo todo o necessário para agradá-lo, inclusive trazendo as mulheres para a cena. A beleza feminina era usada como chamariz, por isso elas apareciam sem a máscara e, inicialmente, eram prostitutas. Em um segundo momento, mulheres cultas vão integrar tais grupos. A principal expoente feminina é Isabela Andreinni, poliglota e uma das atrizes mais famosas do gênero. (Ibid)

Buldrini e Cianfagna (2014) explicam que, nesse período, haviam acordos contratuais rígidos entre os atores, com cláusulas que previam a perda do cachê da turnê em caso de saída do grupo ou afastamento por motivo de doença. A máscara passa a ser um elemento de liberdade para o uso da sátira política e das diferentes classes sociais.

2 "Il teatro della commedia, quello che ha inciso nella storia dello spettacolo di tutta I'Europa per almeno tre secoli, é costruito da gruppi di gente colta, con preparazione e gusto moderni". 
Com o início da censura do uso das máscaras por parte da Igreja, os grupos passam a viajar para a França a partir de 1700, quando a Itália vive o auge do Barroco e o início das óperas. Nesse momento histórico, Buldrini e Cianfagna (2014) relatam que alguns artistas querem deixar de ser bufões e miram o prestígio acadêmico para se apresentar em locais de maior reputação, como a corte real. Isabella Andreinni, integrante de uma das companhias italianas mais famosas do gênero - Gli Gelosi, viveu nesse período.

Essa segunda fase, que vai do século XVIII a XIX, é considerada mais humanizada, com a presença de saltos, acrobacias e elegância nos movimentos, por influência do balé. Aparecem alguns personagens sem máscaras e reis ou comerciantes passam a patrocinar a realização de espetáculos. Isso, contudo, implica em uma redução da liberdade nas escolhas do que iria para a cena, pois os mecenas passam a fazer exigências quanto ao conteúdo da apresentação. (Ibid)

Devido às contínuas restrições impostas pela igreja, a commedia dell'arte vai caindo em desuso, sendo resgatada no século $\mathrm{XX}$ por grupos de teatro modernos e encenadores como Copeau, Ariane Mnouchiknine e o Pícolo Teatro de Milano. Cada um aplicará os conhecimentos tradicionais ao seu fazer teatral, criando corpos diferentes dos típicos arquétipos e com cada ator buscando uma identificação com a máscara. $O$ trabalho de pesquisa com as máscaras também é diferenciado no século 20 e 21 .

\section{PRINCIPAIS CARACTERÍSTICAS DA COMMÉDIA DELL'ARTE}

As principais características da commédia dell'arte são o uso de máscaras, personagens tipos e improvisações chamadas de lazzi. O espetáculo não era, no entanto, totalmente improvisado. Havia uma sequência definida, chamada de canovaccio, no decorrer do qual os personagens incluíam seus lazzi próprios. "Ainda que inventassem variações, a prática da interpretação se dava de pai para filho, de modo muito estruturado." (LECOQ, 2010, p. 176).

A máscara é com certeza o elemento mais visto e aparente, como já dizia Fo (1987, p. 21), que resgata a origem da meia-máscara na Grécia Antiga para explicar a sua função. $O$ formato da boca e o interior das máscaras era construído 
de modo a funcionar como um megafone e, assim, facilitar a projeção vocal, pois era preciso chegar a 20 mil expectadores que assistiam ao teatro nessa época. A meiamáscara da commédia dell'arte "consente uma maior mobilidade expressiva e deixa livre a boca, permitindo assim uma perfeita fonação e uma cômoda respiração" (FORA DE SERIO, 2016).

O cannovacio está baseado nas relações entre servos e patrões e é construído com base em uma variedade de improvisações realizadas a partir das características do personagem, chamadas de Lazzi.

Os cômicos possuíam uma bagagem incrível de situações, diálogos, 'gags', palavreados, jogos tudo guardado na memória, dos quais se serviam no momento justo com grande precisão de tempo, dando a impressão de improvisação naquele instante. Era uma bagagem construída e assimilada com a prática de infinitas réplicas, de diferentes espetáculos, situações montadas até mesmo diretamente com o público, mas a maior parte era, certamente, fruto de exercício e estudo" (Fo, 1987, p. 9, tradução nossa) ${ }^{3}$

Segundo Berthold (2008, p. 353), os lazzi eram "truques pré-armados ou repertório de tramas" que acabavam se tornando as "principais atrações de determinados atores". Lecoq (2010, p. 174) ressalta que o lazzo "sempre enfatiza um elemento da humanidade dos personagens". Segundo o autor (ibid), ao ler o cannovacio de algum espetáculo de commedia dell'arte, o leitor não passará pelos momentos mais interessantes da peça, pois são justamente aqueles sobre o qual não há nada escrito, já que é preenchido com os lazzi dos personagens.

Apenas o ator, por meio de seu jogo e de sua presença cômica, pode fazer com que exista essa parte do texto. A precariedade aparente do roteiro deve-se à dificuldade de pôr no papel o que se deve fazer para ser engraçado, tocante, convincente. Falta o ator em ação. (lbid)

Ao tratar sobre a commedia dell'arte, Lecoq (2010) destaca o que ela traz em termos de temáticas apresentadas. Os espetáculos são construídos em torno de jogos sobre as "grandes trapaças da natureza humana: fazer acreditar, iludir,

3 "I comici possedevano un bagaglio incredibile di situazioni, dialoghi, gags, filastrocche, tiretere tutte riportate a memoria, delle quali si servivano alo momento giusto con grande tempismo, dando l'impressione di improvisare all'instante. Era bagaglio costruito e assimilato con la pratica di infinite repliche, dispettacoli diversi, situazioni montate anche direttamente sul pubblico, ma la maggior parte era, certamente, frutto di esercizio e di studio." 
aproveitar de tudo; os desejos são urgentes; os personagens, em estado de 'sobrevivência'".(Ibid, p.168)

A commédia dell'Arte trabalha os personagens tipos, que são figuras grotescas da sociedade mercantil do século XVI. "Os personagens da comédia italiana navegam permanentemente entre dois polos contraditórios. Arlequim é, ao mesmo tempo, ingênuo e malicioso, o Capitão é forte e medroso, o Doutor sabe tudo e não conhece nada, Pantalone é, ao mesmo tempo, chefe da empresa, senhor de si e totalmente louco no amor. Levada ao máximo, essa dualidade é extremamente rica" (Lecoq, 2010, p.174) Para reforçar a tipificação, os atores se especializavam em um único personagem durante toda a vida, prática comum em alguns gêneros orientais.

Os principais personagens tipos são: Zanni, Enamorados (sem máscaras), Pantalone, Tartaglia, Dottore, Capitano, Arlechino e Briguella. Cada personagem possui um objetivo bem claro. Os enamorados só possuem olhos um para o outro. Dentre os patrões, Pantalone representa os mercadores, tendo como obsessões dinheiro e sexo. Tartaglia é o esteriótipo do funcionário público velho que deseja se casar com uma jovem. Dottore faz referência aos intelectuais, tendo como principais características os longos discursos e o apetite voraz. Capitano retrata o poder militar, sendo caracterizado como estrangeiro conquistador e viajante de terras longínquas.

O chamado Zanni é quem dará origem a todos os servos. Arlecchino é o mais conhecido. Sempre está com fome e, apesar de preguiçoso, é ágil e atrapalhado. Brighella é o brigão e mentiroso, que tenta fazer os outros trabalharem para ele. Outros personagens que foram criados posteriormente são a Pascuela, que representa a sabedoria ancestral e lembra uma bruxa, e Aragonda, uma servente que usa a beleza para conseguir vantagens pessoais.

\section{TREINAMENTO PARA O ATOR}

$\mathrm{Na}$ primeira fase da commedia del'arte, os atores já desenvolviam técnicas corporais e vocais específicas para captar a atenção do público na rua. Há uma codificação do corpo que permite reconhecer facilmente cada personagem, as 
quais foram carregadas ao longo da história da commedia dell'arte e ainda são usadas como ponto de partida por grupos contemporâneos, como foi o caso da Cia Cênica Origem.

Para Buldrini e Cianfagna (2014), a voz é um elemento essencial para a criação do personagem. O processo de descoberta da voz adequada, contudo, está estritamente ligado à pesquisa corporal. Como citado anteriormente, determinadas posturas terão como consequência a colocação da voz em diferentes caixas de ressonância corporal. Um exercício utilizado por Buldrini e Cianfagna (2014) para iniciar essa construção corporal explora o caminhar do personagem segundo a codificação de cada um.

Os atores devem caminhar pelo espaço sendo "puxados" por uma determinada parte do corpo - peito (Capitano), quadril (Pantalone), barriga (Dottore) e bunda (Aragonda). Esse caminhar deve ser sempre em linha reta e triangulando quando for necessário mudar a direção. $O$ ator gira primeiro só a cabeça para a nova direção que pretende ir, volta a cabeça para o público, indicando assim que irá para aquela direção, e só então, volta a cabeça para essa nova direção seguida da virada do corpo a partir da parte que está sendo trabalhada para iniciar a caminhada.

Para manter a atenção do público, outro ponto de grande ênfase na pesquisa prática deve ser na expansão corporal dos atores. Por ter surgido no espaço da rua, a commedia dell'arte exige um nível energético muito elevado de seus atores e uma atenção redobrada aos acontecimentos externos ao espetáculo, os quais podem dar margem para improvisações cômicas. Para alcançá-lo, devem ser feitos exercícios aeróbicos intensivos.

Brincadeiras infantis são excelentes opções para esse fim, tais como pular corda em grupo, jogar peteca, cabra-cega, polícia e ladrão. Além de ajudarem no preparo físico do ator, esses exercícios elevam a energia corporal, aumentam o nível de atenção externa e concentração, elementos que são imprescindíveis para manter um espetáculo de commedia dell'arte até o fim. Vale ressaltar, no entanto, que é preciso ser intensivo porém leve. O caminhar dos atores precisa ser amortecido pelos joelhos. O pisar deve ser leve, evitando assim barulho no assoalho, pois muitas cenas são de correria entre os personagens. A falta desse controle, que pode 
ser alcançado ao colocar a energia corporal no plexo solar, pode levar a uma cena suja e desperdício de energia.

O preparo dos atores da Cia Cênica Origem envolvia todas essas atividades. Além delas, em algumas ocasiões os atores eram colocados em círculo e deviam jogar uma bolinha, um para o outro, contando os números. Paulatinamente, são incluídas novas bolas na roda, com a respectiva inclusão de uma nova contagem de números. Além de trabalhar a atenção do ator, esse é um excelente treino para o jogo, pois todos precisam estar preparados para jogar com o outro e manter o ritmo. Literalmente, os atores não podem deixar a peteca ou a bola cair na commedia dell'arte. "Nessa forma de teatro, para que o corpo fale ao público, afirmamos, ele tem de ser perfeitamente articulado" (Lecoq, 2010, p. 177).

Mesmo os personagens mais lentos, como Dottore ou Tartaglia, precisam ser ágeis para que o jogo aconteça. A agilidade não necessariamente deve ser expressa externamente. Como essa é uma comédia muito baseada no texto, a energia pode ser concentrada em pouca movimentação e uma fala muito ritmada. Textos longos e falados com calma não existem para esses personagens. Tudo é rápido e, portanto, precisa ser curto, como em um jogral.

Quando algum personagem tem alguma fala mais longa, como Dottore, o companheiro de cena deve interromper suas respiradas com sons ou pequenos comentários do tipo "hum”, “ahãm”, "ah!". Buldrini e Cianfagna (2014) explicam que essa colocação de sons nos respiros faz com que o personagem que interage com outro que está dando um grande texto não morra em cena. Em muitas situações, o que está sendo dito nem é o mais importante. O ritmo e o jogo de palavras entre os personagens é o que traz o jogo teatral e, consequentemente, a graça para a cena.

Lecoq (2010, p.171) fala em este estilo ser uma "arte da infância" porque os temas propostos são muito simples e as situações se alteram muito rapidamente. "Arlequim pode chorar a morte de Pantalone e, rapidamente, alegrar-se com a sopa que está pronta!"(Ibid).

Na commedia dell'arte/comédia humana, o estilo de interpretação é levado ao máximo, as situações levadas a seus extremos. O ator atinge um nível muito alto de interpretação, e o público pode observar as consequências de um comportamento....até a morte. Neste caso, falsa! (Lecoq, 2010, p. 172) 


\section{CONCLUSÕES}

Lecoq (2010, p. 178) diz que muitas pessoas do teatro contemporâneo sonham em pesquisar a commedia dell'arte para renovar os arquétipos e trazê-los para o contexto sociopolítico atual. Contudo, segundo o autor, isso não seria possível devido ao caráter imutável das relações sociais. Essa comédia mostra a natureza humana, a qual não se altera com o passar dos anos. "A commedia dell'arte está em todos os lugares, em todos os tempos, enquanto houver patrões e servidores indispensáveis a seu jogo" (ibid). Por isso, em diferentes momentos históricos, é possível identificar peças teatrais que incorporam elementos similares aos da commedia dell'arte.

Além da questão temática dos espetáculos, a grande contribuição da pesquisa com esse gênero para o teatro contemporâneo talvez seja no intenso trabalho corporal e de preparação vocal exigido dos atores da commedia dell'arte para atingir um nível de interpretação levado ao máximo. O cômico será alcançado apenas quando a criação do personagem estiver bem consolidada, incluindo a clareza do ator sobre as vontades e contra-vontades individuais. Seja qual for a estética adotada por grupos teatrais da atualidade, essas são qualidades imprescindíveis para alcançar um bom resultado.

A partir das experiências da Companhia Cênica Origem apresentadas nesse artigo, é possível perceber que a adoção de práticas típicas de preparo de atores da commedia dell'arte tradicional no cotidiano de grupos teatrais contemporâneos pode colaborar com o alcance de um corpo mais disponível em cena e um trabalho vocal mais aguçado.

\section{REFERÊNCIAS}

BERTHOLD, Margot. História Mundial do Teatro. 3.ed. São Paulo: Editora Perspectiva, 2006.

BULDRINI, Massimiliano; CIANFAGNA, Paula Noelia. Oficina Commedia dell'arte, ministrada em Florianópolis, 2014 
ENCYCLOPAEDIA Britannica. Lazzo. Disponível em: <http://global.britannica.com/art/lazzo> (acessado em 07/03/2016).

FORA DO SERIO. Máscaras da Commedia Dell'Arte. Disponível em: $<$ http://www.foradoserio.net/cdac.htm> (acessado em 13.03.2016).

LECOQ, Jacques. O corpo poético: uma pedagogia da criação teatral. São Paulo: Editora Senac São Paulo: Ediçõe Sesc São Paulo SP: 2010.

FO, Dario. Manuale mínimo dell'attore.Torino: Einaudi, 1987 